\title{
A Corpus-based Study on the Use of MAKE by Turkish EFL Learners
}

\author{
M. Pinar Babanoğlu \\ Sütçü İmam Univrsity, \\ Avşar Campus, 46100, \\ Kahramanmaraş, Turkey \\ E-mail: pinarbab@hotmail.com
}

Received: 08-02- 2013

Accepted: 25-03-2013

Published: 30-04-2014

doi:10.7575/aiac.ijels.v.2n.2p.43

URL: http://dx.doi.org/10.7575/aiac.ijels.v.2n.2p.43

\begin{abstract}
This study examines the lexical and grammatical use of a high frequency verb 'MAKE' by Turkish EFL learners. Major goals are to investigate whether Turkish learners of English use MAKE appropriately in their argumentative essays and to see to what extent L1 transfer plays a role in such usage and to what extent different learner groups from different L1s share common interlanguage features. Overuse, underuse and misuse of MAKE by learners and native speakers gathered by frequency calculations from native speakers' and two learners' corpora and comparison of them among each other constitute the quantitative backbone of the research. Results showed that Turkish learners have difficulty in the use of MAKE to a certain degree. Consequently, learners should be made aware of especially delexical and grammatical patterning of high frequency verbs in English such as MAKE and they should also be shown the difference in the use of these verbs between their L1 and L2.
\end{abstract}

Keywords: Learner Corpus, High frequency verbs in English, L1 Transfer

\section{Introducation}

In interlanguage, using word combinations such as 'make a decision' properly is an important part for a high degree of competence in second language (Nesselhauf, 2005). These constructions are called 'delexical structures' (Sinclair, 1990) which are characterized as collocations because of their semantically restricted features, e.g. 'make a decision' instead of'do a decision' (Juknevičienè, 2008). Correspondingly, numerous studies show that learners face problems in the comprehension and the production of such structures due to this restrictive and transparent nature (Ringbom, 1998; Woolard, 2000; Altenberg and Granger, 2001; Nesselhauf, 2005; Kennedy, 2005; Juknevičienė, 2008). Kennedy (2005) states that the collocations of high frequency English lexical verbs are highly selective in the types of objects they take, e.g. 'we end war' not 'finish war, we 'start afresh' but not 'begin afresh', we 'lose weight' but don't 'receive' it, and 'receive support' not 'loose' it. Sinclair (1991) states that EFL learners tend to avoid using collocations and instead they rely on larger, rarer and clumsier words which make their language stilted and awkward. Therefore, high frequency verbs as MAKE and their grammatical and lexical patterning seem to be problematic for EFL learners as well. However, Pawly and Syder(1983) states that collocational knowledge is indispensable for language learners to produce fluent and appropriate language since it is the essence of language knowledge. Because many words are used in a limited set of collocations / multi-word units, knowing their collocational possibilities should be one essential aspect of language learning (Wang and Show, 2008). Ringbom (1998) investigated most frequent vocabulary within learner corpora from different L1 backgrounds and found that MAKE (disregarding 'be' and auxiliaries) is the most frequent main verb in NS (native speaker) corpus and also favored in NNS (non-native speaker) corpora after the verbs THINK and GET.

\subsection{Research Questions}

1. Is there significant difference between EFL learners and native English spkeakers in the total use of 'MAKE'?

2. Is there significant difference between two EFL learner groups in the total use of 'MAKE'?

3. Which categories of MAKE do EFL learners prefer to use?

4. Is there any L1 transfer trace in the use of 'MAKE' by EFL learners?

\section{Method}

In the present study, Turkish Corpus of Learner English (henceforth TICLE) and Japanese Corpus of Learner English (henceforth JPICLE) which are Turkish and Japanese sub-corpus from International Corpus of Learner English (ICLE) database have been utilized as learner data. ICLE corpus consists of argumentative essays of EFL learners from several L1 backgrounds. Louvain Corpus of Native English Essays (LOCNESS) utilized as the native speaker control group to compare learners' use of MAKE. Sizes of TICLE and JPICLE as EFL learner group and LOCNESS as native group corpora are shown in Table 1. 
Table 1. NNS and NS corpora

\begin{tabular}{llll} 
& TICLE & JPICLE & LOCNESS \\
\hline Number of words & 169.345 & 168.160 & 168.325 \\
Number of essays & 280 & 315 & 207
\end{tabular}

Amounts of three corpora are close together though the numbers of essays are different since the native speaker essays are a bit longer than essays of non-native speakers (Granger, 2008). Frequency calculations of grammatical and lexical uses of MAKE gathered from three corpora have been compared by Log-likelihood ratio to see statistical differences. Overuse and underuse of MAKE would give the opportunity to clarify the usage difference between learner groups whereas misuse of MAKE in collocations might be an indicator in terms of L1 transfer.

\section{Results}

The overall frequency of MAKE used by learners and native speakers is shown in Figure 1. As demonstrated in the graph, total amounts of MAKE within three corpora are slightly different, in fact both learner corpora showed a moderate underuse when compared to native speaker corpora.

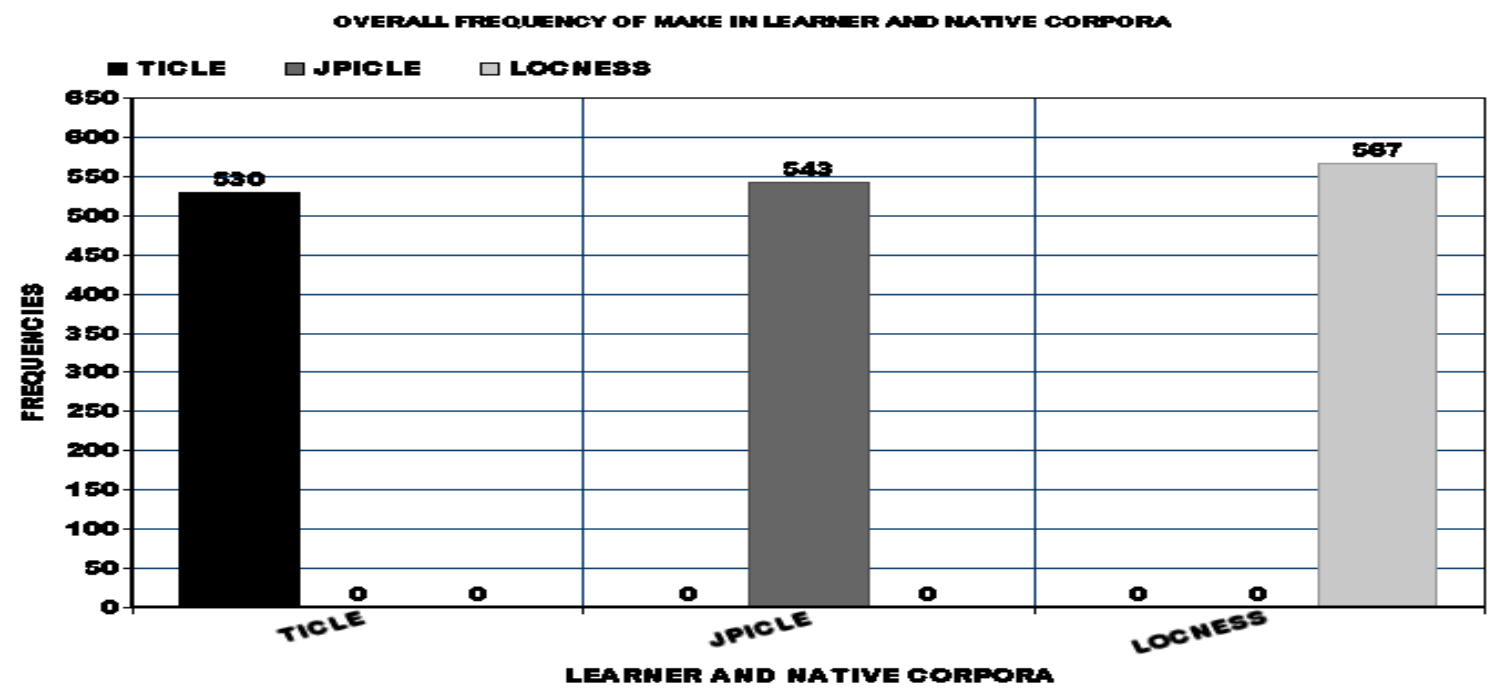

Figure 1. Overall frequencies of MAKE in learner and native corpora.

To understand whether these differences are statistically significant, Log-likelihood (LL) ratio of corpora was measured considering the frequency of MAKE and each corpus size. As L2 vs. L1, LL ratio between TICLE and LOCNESS JPICLE and LOCNESS was measured for L2 vs. L1, and LL ratio of TICLE and JPICLE for L2 vs. L2. Table 2presents overall LL ratio among three corpora:

Table 2. Log-likelihood ratio (LL) of overall frequency of MAKE among learnerand native corpora.

TICLE vS. LOCNESS

LL

MAKE
JPICLE vS. LOCNESS

LL

$0.50-$
TICLE vs. JPICLE

LL

$0.26-$

$p<0.05$ (critical value: 3.84 ) + indicates overuse in the first corpus relative to the second corpus

-indicates underuse in the first corpus relative to the second corpus

According to the results, there is not a significant difference between learner and native corpora and between each learner corpora.

Next measurement was made in the categorical uses of MAKE in which eight major categories (Altenberg and Granger, 2001, p. 177):

1. Produce sth (result of a creation)

2. Delixal uses

3. Causative uses

4. Earn (money)

5. Link verb uses

6. Make it

7. Phrasal/prepositional uses

8. Other conventional uses make furniture, make a hole, make a law make a distinction, decision, a reform make sb believe sth, make sth possible make a fortune, a living She will make a good teacher If we run, we should make it make out, make up, make out of make good, make one's way 
In order to sort the categorical uses of MAKE, Wordsmith Tools (2008) concordance tool has been applied over three corpora. The aim of this analysis was to see the situation of different uses by learner and native speaker and how these uses are classified by means of eight categories. Table 3. shows the frequency of each categorical uses of MAKE by learners and native speakers in their essays:

Table 3. Frequencies of uses of MAKE in learner and native corpora.

\begin{tabular}{llcc} 
Categories & TICLE & JPICLE & LOCNESS \\
\hline Produce & 32 & $\mathbf{3 7}$ & 27 \\
Delexical & 204 & $\mathbf{2 5 4}$ & 187 \\
Causative & $\mathbf{2 6 4}$ & 209 & $\mathbf{2 3 6}$ \\
Money & 14 & 8 & 56 \\
Link verb uses & 1 & 4 & 7 \\
Make it & - & 2 & 6 \\
Phrasal & 10 & 27 & 22 \\
Other & 5 & 2 & 26 \\
TOTAL & $\mathbf{5 3 0}$ & $\mathbf{5 4 3}$ & $\mathbf{5 6 7}$ \\
\hline
\end{tabular}

Results of frequency analysis of each category in corpora revealed that causative and delexical uses are most commonly used types of MAKE in three corpora. Turkish learners and native speakers used causative type structures of MAKE such as 'make someone happy'whereas Japanese learners preferred delexical MAKE like 'make friends'. Consequently, Turkish learners seemed to overuse causative forms and Japanese learners overused delexical forms in their essays. To see as to whether such overuses by learners serve a statistical significance, LL ratio was measured among three corpora which are presented in Table 4.

Table 4. Log-likelihood (LL) ratio of different uses of MAKE in NNS and NS corpora.

\begin{tabular}{llll} 
& $\begin{array}{c}\text { TICLE vs. LOCNESS } \\
\text { LL }\end{array}$ & $\begin{array}{c}\text { JPICLE vs. LOCNESS } \\
\text { LL }\end{array}$ & $\begin{array}{c}\text { TICLE vs. JPICLE } \\
\text { LL }\end{array}$ \\
\hline Produce & $0.39+$ & $1.58+$ & $0.40-$ \\
Delexical & $0.64+$ & $\mathbf{1 0 . 2 8 + *}$ & $\mathbf{5 . 8 3}-^{*}$ \\
Causative & $1.40+$ & $1.61-$ & $\mathbf{6 . 0 3}+^{*}$ \\
Money & $\mathbf{2 7 . 2 4 - *}$ & $\mathbf{4 0 . 4 5 - *}$ & $1.62+$ \\
Link verb uses & $5.10-^{*}$ & $0.83-$ & $1.95-$ \\
Make it & $\mathbf{8 . 3 5 - *}$ & $2.09-$ & $2.79-$ \\
Phrasal & $\mathbf{4 . 6 8 - *}$ & $0.52+$ & $\mathbf{8 . 2 3}-*$ \\
Other & $\mathbf{1 5 . 7 1 - *}$ & $\mathbf{2 4 . 3 8 - *}$ & $1.31+$ \\
\hline
\end{tabular}

$p<0.05$ (critical value: 3.84 ) + indicates overuse in the first corpus relative to the second corpus; - indicates underuse in the first corpus relative to the second corpus

According to LL results, there is a significant difference in delexical uses between Japanese learners and native speakers and between Japanese learners and Turkish speakers which meant that delexical MAKE was overused by Japanese EFL learners. On the other hand, frequency difference of causative MAKE between Turkish learners and Japanese learners present a statistical significance of an overuse. Other marked differences can be seen in money forms like 'make money, make profit' which Turkish learners and Japanese learners significantly underused when compared to native speakers. Similarly, phrasal, 'make it' category and other categories showed underuse by Turkish learners and also Japanese learners underused other uses of MAKE.

When delexical MAKE's collocational structures taken into consideration individually, learners and native speakers opted diverse nouns as the collocation of MAKE.

Table 5. Frequency of Top 10 Collocations of Delexical MAKE in NNS an NS Corpora.

TICLE

\begin{tabular}{llllll}
\hline $\begin{array}{c}\text { Collocation } \\
\text { of MAKE }\end{array}$ & f & $\begin{array}{l}\text { Collocation } \\
\text { of MAKE }\end{array}$ & f & $\begin{array}{c}\text { Collocation } \\
\text { of MAKE }\end{array}$ & f \\
\hline decision & 30 & use & 29 & decision & 31 \\
use & 14 & friend & 25 & mistake & 16 \\
mistake & 10 & effort & 20 & choice & 10 \\
research & 9 & progress & 16 & argument & 9 \\
effort & 5 & mistake & 16 & claim & 9 \\
choice & 6 & call & 7 & point & 8 \\
change & 6 & atmosphere & 5 & statement & 8 \\
effort & 5 & state & 5 & case & 5 \\
plan & 3 & point & 3 & error & 5 \\
call & 3 & choice & 3 & effort & 4
\end{tabular}


Both Turkish learners and native speakers mostly used decision as 'make a decision' in similar amounts. Japanese learners highly used use as in 'make use' in which Turkish learners also showed a similar performance. In three corpora, mistake, choice and effort are other commonly applied collocations following MAKE in a sentence.

\subsection{Error Analysis of Misuses}

Two learner corpora contain inappropriate uses of MAKE that may be due to either L1 transfer effects or selective and transparent nature of the collocations. Turkish learners preferred to use 'make a research' instead of 'do a research' or 'make exercise' instead of 'do exercise' or 'make presentation' instead of 'do presentation' which seem to be a confusion of make vs. do:

1. "A student model which makes research and improve him/herself from different aspects is not seen. " (TICLE/TRME.3002.txt).

2. "Most universities follow this order about making research while teaching their theoretical field knowledge"(TICLE/TRME.3026.txt)

3. "Teachers say how to present a lesson, make exercises, draw attention of students and..." (TICLE/TRCU.1071.txt)

4. "....sometimes we make presentations in our classes..." (TICLE/TRCU.0071.txt)

Such uses of do vs. make don't exist in Japanese data but in some cases, different verbs used instead of MAKE for certain collocations in JPICLE for example 'give' instead of 'make':

5. $\quad$ "If the person has the ability and gives effort, they are able to do the job." (JPICLE/JPWA.1017.txt)

6. "......... sort of radio wave, which gives damage for our brain." (JPICLE/JPSW.4007.txt)

7. "In addition, if we can talk in the formal style, we will give a good impression to other people." (JPICLE/JPSW.4032.txt)

In Turkish learner data, verb 'give' used on behalf of MAKE which might be an indication of L1 transfer. Students used 'give' against 'make' with decision in some cases, for instance:

8. "The important thing is to think enough and to give the right decision at the right time! " (TICLE/TRCU.1094.txt)

9. "Therefore, the authority gave the most terrible decision of judgements,.." (TICLE/TRCU.1105.txt)

10. "There was a play about the euthanasia called "Who Gives The Decision?".." (TICLE/TRCU.1105.txt)

In Turkish, the equivalent of 'decision' is 'karar' which is collocated with verb 'vermek' corresponding with 'give' in English. For example:

English: make a decision $==>$ Turkish: bir karar vermek

(det.) (noun)

(det.) (noun) (verb)

(a) (decision) (give)

Verb 'give' means 'vermek' in Turkish whereas verb 'make' means 'yapmak', therefore students may tend to use 'give' instead of 'make' in order to collocate with 'decision'. In the same way, in Turkish, one of the uses of 'make a decision' in Turkish is 'karar almak' in which the verb 'almak' means 'take' in English. Such a combination can be seen in Turkish data as:

11. "As the state takes the decision of death for the guilties according to the laws,." (TICLE/TRCU.1119.txt)

12. "So it is not an easy decision for a relative to take. " (TICLE/TRCU.1159.txt)

In Turkish data, similar condition is notable for another collocation 'make effort' which has a different transformation into Turkish as illustrated below:

English: make effort $\quad==>\quad$ Turkish: çaba harcamak /göstermek

(verb) (noun)

(effort) (spend) / (show)

(noun) (verb) / (verb)

This situation can be noticed in some cases in the Turkish data:

13. "..,they do not show enough effort to learn the required things. " (TICLE/TRMR.3017.txt)

14. "We do not have to spend much effort to find some evidence to prove this fact; .." (TICLE/TRCU.1135.txt)

15. "Otherwise why do people spend so much effort to be able to a university student?" (TICLE/TRCU.1072.txt)

Turkish students are likely to use the translation of Turkish equivalent verb of certain collocations which normally used with MAKE in English. They tend to use 'give decision' or 'take a decision' instead of 'make a decision' and 'spend effort' or 'show effort' instead of 'make effort'. Since these kinds of misuses haven't been identified in Japanese learners' data, it can be inferred that these usages are language specific and L1 effected. 
Considering the general results, Altenberg \& Granger's (2001) research results were confirmed in this study. Two upper intermediate-advanced EFL groups were shown difficulty in patterning MAKE as stated in Altenberg \& Granger (2001). In the light of the overall results, research questions have been answeres as follows:

1. R.Q.1. Is there significant difference between EFL learners and native English spkeakers in the total use of 'MAKE'?

No statistically significant difference detected between EFL learners and native English speakers in overall frequency of MAKE.

2. Is there significant difference between two EFL learner groups in the total use of 'MAKE'?

Turkish and Japanese learners showed a similar performance in the use of MAKE in total and there is not a signicant difference between them.

3. Which categories of MAKE do EFL learners prefer to use?

Turkish EFL learners present a smiliar attitude as native English speakers in using 'produce', 'causative' and 'delexical' usage of MAKE except they tended to use causative MAKE significantly more than Japanese learners. On the other hand, Japanese learners used 'causative' and 'delexical' MAKE considerable more than native speakers and Turkish learners.

4. Is there any L1 transfer trace in the use of 'MAKE' by EFL learners?

In error analysis, some type of L1 transfer taste can be seen Turkish learners' usage of MAKE, e.g. collocations as 'give decision' (as the way it is used in Turkish phrase) instead of 'make a decision'.

\section{Conclusion}

In the study, analyzing the lexical and grammatical patterning of a high frequency verb MAKE showed various outputs by Turkish and Japanese learners. In total, both learner groups exhibited a similar performance in the use of MAKE in general when compared to native speakers. Categorically, overuse and underuse conditions are in question by both learners whereas error prone MAKE collocations are becoming prominent. However, the error types identified in Turkish and Japanese learner corpora seem to be different in meaning since they showed differences in their incorrect usage. Japanese learners' misuses of MAKE collocations might be due to verb combination confusions which may be due to L2 instructions given whereas Turkish learners made specific errors that might have originated from L1 transfer.

L2 instruction based or L1 transfer sourced, errors by learners can be overcome by consciousness -raising on L1-L2 differences with proper EFL materials. Indeed, using concordance technique of usage of MAKE (like other high frequency verbs DO, GET, etc.) in the original texts and exercises may be beneficial for learners to focus on collocations.

\section{References}

Alternberg, B. \& Granger, S. (2001). The grammatical and lexical patterning of make in native and non-native student writing. Applied Linguistics 22(2), 173-194.

Ellis, N.C., Frey, E. \& Jalkanen, I. (2009). The psycholinguistic reality of collocation and semantic prosody. In Römer, U. \& Schulze, R. (Eds.) Exploring the Lexis-Grammar Interface. Amsterdam: Benjamins

Juknevičienè, R. (2008). Collocations with high-frequency verbs in learner English: Lithuanian learners vs native speakers.Kalbotyra 59 (3): 119-127.

Nesselhauf, N. (2005). Collocations in Learner Corpus. Amsterdam: Benjamins.

Pawley, A. \& Syder, F.H. (1983). Two puzzles for linguistic theory: nativelike selection and nativelike fluency. In: J.C. Richars \& R.W. Schmidt (Eds.) Language and communication,.191-226. London: Longman.

Ringbom, H. (1998). Vocabulary frequencies in advanced learner English: a cross-linguistic approach. In Granger, S. (ed.) Learner English on Computer, 41-52. London \& New York: Addison Wesley Longman.

Scott, M., (2008). WordSmith Tools version 5, Liverpool: Lexical Analysis Software.

Sinclair, J. (1991). Corpus, Concordance, Collocation. Oxford: OUP.

Woolard, G. 2000. Collocation - encouraging learner independence. M. Lewis (ed.) Teaching Collocation. Further developments in the lexical approach, 28-46. Hove: Language Teaching Publications. 